\title{
Flow-aligned jets in the magnetospheric cusp: Results from the Geospace Environment Modeling Pilot Program
}

Article

Published Version

Weiss, L. A., Reiff, P. H., Weber, E. J., Carlson, H. C., Lockwood, M. and Peterson, W. K. (1995) Flow-aligned jets in the magnetospheric cusp: Results from the Geospace Environment Modeling Pilot Program. Journal of Geophysical Research, 100 (A5). p. 7649. ISSN 0148-0227 doi: https://doi.org/10.1029/94JA03360 Available at https://centaur.reading.ac.uk/38806/

It is advisable to refer to the publisher's version if you intend to cite from the work. See Guidance on citing.

Published version at: http://dx.doi.org/10.1029/94JA03360

To link to this article DOI: http://dx.doi.org/10.1029/94JA03360

All outputs in CentAUR are protected by Intellectual Property Rights law, including copyright law. Copyright and IPR is retained by the creators or other copyright holders. Terms and conditions for use of this material are defined in the End User Agreement. 


\section{CentAUR}

Central Archive at the University of Reading

Reading's research outputs online 


\title{
Flow-aligned jets in the magnetospheric cusp: Results from the Geospace Environment Modeling Pilot program
}

\author{
L. A. Weiss, ${ }^{1,2}$ P. H. Reiff, ${ }^{1}$ E. J. Weber ${ }^{3}$ H. C. Carlson, ${ }^{3}$ M. Lockwood ${ }^{4}$ \\ and W. K. Peterson ${ }^{5}$
}

\begin{abstract}
The extended flight of the Airborne Ionospheric Observatory during the Geospace Environment Modeling (GEM) Pilot program on January 16, 1990, allowed continuous all-sky monitoring of the two-dimensional ionospheric footprint of the northward interplanetary magnetic field (IMF) cusp in several wavelengths. Especially important in determining the locus of magnetosheath electron precipitation was the $630.0-\mathrm{nm}$ red line emission. The most striking morphological change in the images was the transient appearance of zonally elongated regions of enhanced 630.0-nm emission which resembled "rays" emanating from the centroid of the precipitation. The appearance of these rays was strongly correlated with the $Y$ component of the IMF: when the magnitude of $B_{y}$ was large compared to $B_{z}$, the rays appeared; otherwise, the distribution was relatively unstructured. Late in the flight the field of view of the imager included the field of view of flow measurements from the European incoherent scatter radar (EISCAT). The rays visible in 630.0-nm emission exactly aligned with the position of strong flow jets observed by EISCAT. We attribute this correspondence to the requirement of quasineutrality; namely, the soft electrons have their largest precipitating fluxes where the bulk of the ions precipitate. The ions, in regions of strong convective flow, are spread out farther along the flow path than in regions of weaker flow. The occurrence and direction of these flow bursts are controlled by the IMF in a manner consistent with newly opened flux tubes; i.e., when $\left|B_{y}\right|>$ $\left|B_{z}\right|$, tension in the reconnected field lines produce east-west flow regions downstream of the ionospheric projection of the $\mathrm{x}$ line. We interpret the optical rays (flow bursts), which typically last between 5 and $15 \mathrm{~min}$, as evidence of periods of enhanced dayside (or lobe) reconnection when $\left|B_{y}\right|>\left|B_{z}\right|$. The length of the reconnection pulse is difficult to determine, however, since strong zonal flows would be expected to persist until the tension force in the field line has decayed, even if the duration of the enhanced reconnection was relatively short.
\end{abstract}

\section{Introduction}

In an open magnetosphere, the cusps are funnel-shaped regions of open field lines. Particles which gain entry onto these field lines through magnetic reconnection at the dayside magnetopause may therefore precipitate directly into the ionosphere. Cusp field lines are magnetically connected to the ionosphere in a localized region near $12 \mathrm{MLT}$; as these field lines convect antisunward over the polar caps, they form the high-latitude boundary layer (mantle). Extending in local time on either side of the cusp is the cleft, whose (presumably closed) field lines map to the low-latitude boundary layer

\footnotetext{
${ }^{1}$ Department of Space Physics and Astronomy, Rice University, Houston, Texas.

${ }^{2}$ Now at Los Alamos National Laboratory, Los Alamos, New Mexico.

${ }^{3}$ Phillips Laboratory, Hanscom Air Force Base, Massachusetts.

${ }^{4}$ Rutherford Appleton Laboratory, Chilton, England.

${ }^{5}$ Lockheed Palo Alto Research Laboratory, Palo Alto, California.
}

Copyright 1995 by the American Geophysical Union.

Paper Number 94JA03360.

0148-0227/95/94JA-03360\$05.00
(LLBL) along the flanks of the magnetosphere [Reiff, 1979; Heikkila, 1985; Newell and Meng, 1988]. The open field line portion of the LLBL (mapping to the low-altitude cleft equatorward of the cusp) consists of such recently merged field lines that only the highest-energy magnetosheath plasma has had time to precipitate [Reiff et al., 1977; Onsager et al., 1993; Lyons et al., 1994].

The primary method of distinguishing the ionospheric projections of the cusp, mantle, and LLBL is through the classification of low-altitude particle precipitation, although plasma flow, optical, and magnetic characteristics may also be used. Ions injected at the dayside magnetopause undergo a time-of-flight dispersion as they travel to the ionosphere, resulting in a precipitation signature which decreases in energy with increasing latitude for southward interplanetary magnetic field (IMF) conditions [Shelley et al., 1976; Reiff et al., 1977]. The precipitating fluxes are largest slightly downstream of the last closed field line, where the ions with the highest phase space density (near $1 \mathrm{keV}$ ) precipitate [Onsager et al., 1993]. As injected ions enter the tail lobe, the supply of plasma to low altitudes is cut off because the magnetosheath source flow becomes super-Alfvénic and tailward [Hill and Reiff, 1977; Onsager et al., 1993]. Based on thousands of passes of DMSP data, Newell and Meng [1988, 1989] classify the low-altitude cusp as a region of intense, structureless, low-average-energy electron and ion precipitation, while cleft (LLBL) precipitation is characterized 
by more structure, lower flux, and higher average energy. The ionospheric footprint of the mantle, poleward of the cusp proper, is identified as the low-energy tail of the dispersed precipitation [Newell et al., 1991]. Midaltitude measurements from DE 1 showed that these low-energy precipitating ions are associated with upgoing higher-energy ions which have mirrored at lower latitudes and thus will form the inner part of the plasma mantle [Burch et al., 1982]. Observations of a reversed ion dispersion signature, indicative of sunward convection from lobe reconnection, have been observed for $B_{Z}>0$ [Burch et al., 1980, 1986; Escoubet and Bosqued, 1989; Woch and Lundin, 1992; Basinska et al., 1992]. At midaltitudes, the general dispersion signatures are also observed as a series of V's due to the pitch angle dependence of the field-aligned ion transit time [Burch et al., 1982; Menietti and Burch, 1988].

The locus of cusp precipitation and the direction of cuspregion plasma flow are strongly dependent on the direction of the IMF. For instance, particle measurements have shown that cusp precipitation shifts (1) equatorward during intervals of $B_{\mathbf{Z}}$ $<0$ [e.g., Burch, 1973; Reiff et al., 1980; Carbary and Meng, 1986; Newell et al., 1989], (2) toward dawn for $B_{y}<0\left(B_{y}>0\right)$ in the northern (southern) hemisphere, and (3) toward dusk (or remaining near noon) for $B y>0(B y<0)$ in the northern (southern) hemisphere [Candidi et al., 1983; Newell et al., 1989; Aparicio et al., 1991]. (The $B_{y}$ shift is more apparent for $B_{z}<0$ than $B_{z}>0$ ). The direction of cusp-region plasma flow is predominately (1) antisunward (sunward) for $B_{Z}<0\left(B_{Z}\right.$ $>0$ ), (2) toward dawn for $B_{y}>0\left(B_{y}<0\right)$ in the northern (southern) hemisphere, and (3) toward dusk for $B y<0\left(B_{y}>0\right)$ in the northern (southern) hemisphere [e.g., Reiff and Burch, 1985; Heppner and Maynard, 1987]. The convection throat is located slightly on the prenoon side (in the corotating frame) regardless of the sign of $B_{y}$ for a gardenhose IMF orientation [Heelis, 1984], while in the inertial frame the convection is more symmetric around noon [Maynard et al., 1991b]. High time resolution radar measurements of flow direction on newly opened field lines (equatorward edge of the cusp for southward IMF) indicate that the east-west flow direction in the cusp responds very rapidly (of the order of a few minutes) to a reversal in IMF $B_{y}$ [Clauer and Banks, 1986; Etemadi et al., 1988; Greenwald et al., 1990]. Observations of plasma flow reversals at low magnetopause latitudes also clearly support $B_{y}$ dependent asymmetric polar cap convection. The $B y$ effect is attributed to tension in the newly opened field lines which alters the direction of ionospheric plasma flow [Cowley et al., 1983, 1991; Reiff and Burch, 1985; Saunders, 1988; Gosling et al., 1990; Maynard et al., 1991 a].

The question of whether the cusp arises from quasi-steady or transient reconnection is an important ongoing controversy. Although pulsed reconnection can yield a persistent cusp feature (assuming the repetition rate is faster than the ion precipitation time), it will create a discontinuous energy / latitude dispersion signature. A continuous energy / latitude dispersion signature, on the other hand, indicates quasistationary reconnection, injection, and convection. As we will show below, even continuous reconnection can cause a discontinuous dispersion signature, if the convective flow has a substantial, variable, component across the satellite trajectory [Reiff, 1990]. There is ample evidence for periods of apparently continuous reconnection at the magnetopause [e.g., Sonnerup et al., 1981; Gosling et al., 1982, 1986; Paschmann et al., 1986, 1989] and for correspondingly quasi- steady cusp ion dispersion signatures [e.g., Reiff et al., 1977; Hill and Reiff, 1977; Frahm, 1984; Aparicio et al., 1991; Mukai et al., 1991; Phillips et al., 1993]. There is also evidence supporting transient dayside merging, or flux transfer events (FTEs) [e.g., Russell and Elphic, 1979; Saunders et al., 1984], their ionospheric flow jet signatures [Lockwood et al., 1989a; Elphic et al., 1990], and the correspondingly impulsive cusp ion dispersion signatures [e.g. Saflekos et al., 1990; Bosqued et al., 1991; Escoubet et al., 1992; Lockwood and Smith, 1992; Yamauchi and Lundin, 1994]. It may also be possible that ionospheric flow bursts are caused by transients in the sheath magnetic field rather than in the reconnection rate [Newell and Sibeck, 1993], although Lockwood et al. [1994] dispute that possibility. In any case, it is likely that the cusp exhibits spatial or temporal enhancements superimposed on a background, steady state cusp driven by quasi-steady state reconnection on the dayside, at least for southward IMF [Smith and Lockwood, 1990; Southwood et al., 1988; Scholer, 1988].

Recently, increased emphasis has been placed on studying magnetopause and boundary layer processes through the use of low-altitude and ground-based observations. Because of the requirement of quasi-neutrality, magnetosheath electrons precipitate with the injected ions, exciting $630.0 \mathrm{~nm}$ emissions and, to a lesser degree, emissions at $557.7 \mathrm{~nm}$, $427.8 \mathrm{~nm}$, and $391.4 \mathrm{~nm}$. These emissions can be monitored by appropriately positioned photometers and all-sky cameras [e.g., Sandholt et al., 1985; 1986a, b; Oguti et al., 1988; Sandholt and Newell, 1992]. Likewise, density enhancements and ion flow irregularities in the dayside ionosphere may be probed using radars, which can provide high time resolution information on the density, temperature, and flow characteristics of the cusp and cleft regions [Goertz et al., 1985; Todd et al., 1986; Greenwald et al., 1990; Lockwood et al., 1989b, 1993; Watermann et al., 1992; Baker et al., 1990, this issue]. The Geospace Environment Modeling (GEM) Pilot program, on January 16, 1990 [Carlson and Basu, 1990], was designed as an intercalibration experiment to acquire joint ground-based, aircraft, and satellite data for the purpose of identifying the ionospheric signatures of the magnetospheric cusp and cleft. The Phillips Laboratory's Airborne Ionospheric Observatory (AIO) flew a course over the northern polar cap that kept it between $75^{\circ}$ and $80^{\circ}$ invariant latitude and within an hour of 12 MLT for over 5 hours. The AIO collected all-sky image, sounder, spectrometer, and scintillation data of the magnetospheric cusp during the flight. During the latter part of the flight, the field of view of the all-sky imager overlapped the field of view of the EISCAT radar. This paper will report the results of the coordinated optical, radar, and IMF data during the GEM Pilot program.

\section{Observations}

The flight path of the AIO, DE 1 satellite overflight, and the EISCAT field-of-view are shown in polar geographic coordinates in Figure 1. The 8-hour flight originated at Eielson Air Force Base, Alaska and ended at Andoya, Norway. From 0400 to 0645 UT the AIO, while keeping the dayside aurora in its field of view, remained within $\pm 15 \mathrm{~min}$ of noon magnetic local time. From 0645 to $0800 \mathrm{UT}$ it drifted into the prenoon sector, crossing local times ranging from 1100 to 1040 MLT. IMF data, shown in Figure 2, are available from 


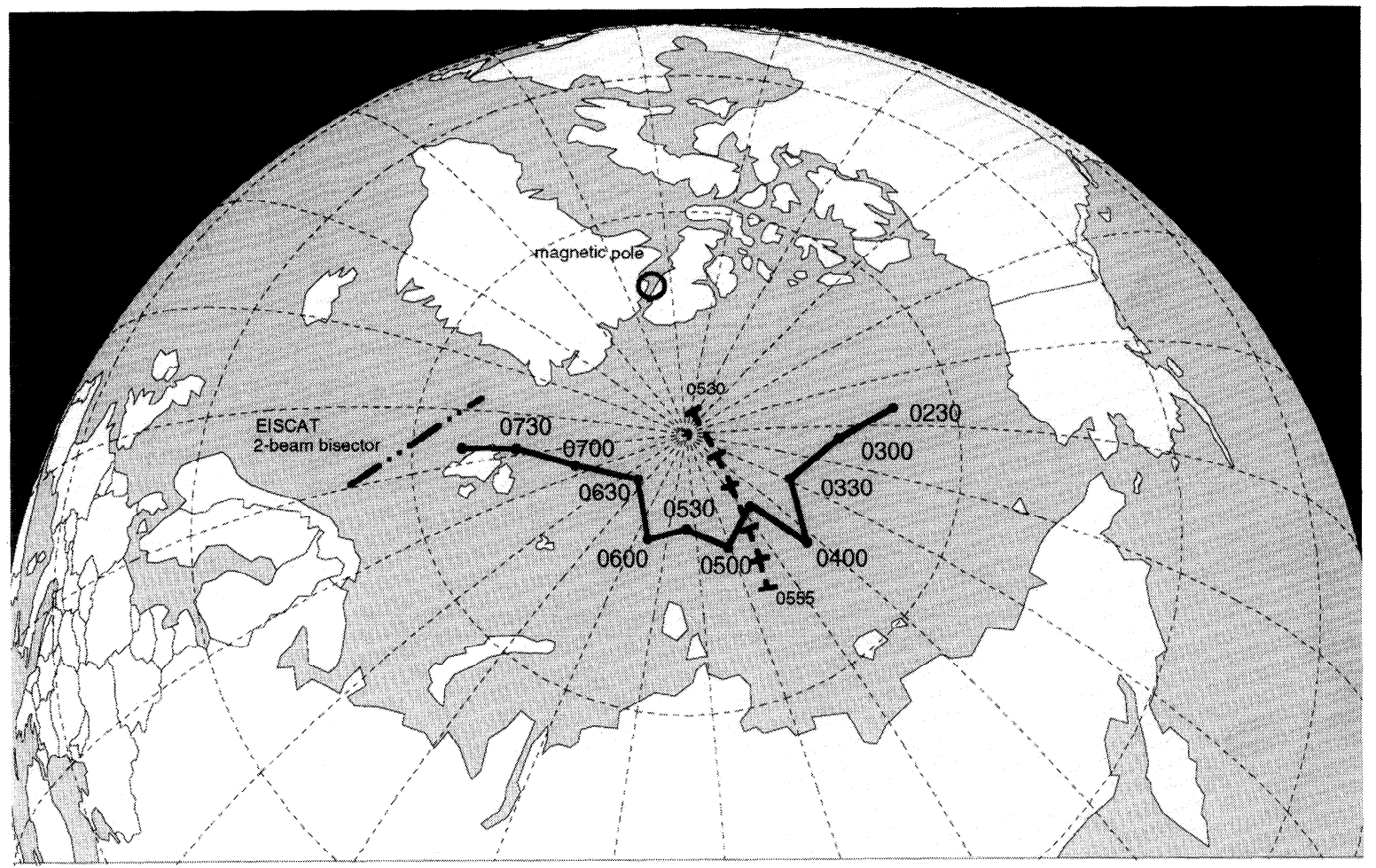

Figure 1. Polar geographic projection of the flight path of the AIO aircraft between 0230 and 0800 UT. The ground track of the DE 1 spacecraft (mapped to $250 \mathrm{~km}$ ) is shown between 0530 and 0555 UT. From 0400 to 0645 UT the AIO adjusted its course to remain close to noon MLT while staying under the region of strongest $630.0-\mathrm{nm}$ emission. The aircraft intercepted the EISCAT field of view near 0800 UT.

0530 UT onward. The $B_{z}$ component was weakly northward during this period and $B y$ was positive, becoming negative only briefly from $\sim 0640$ to 0655 UT. The $K p$ 3-hour indices $(3-, 3,2)$ for the first half of January 16 indicate relatively quiet magnetospheric conditions.

During the flight the all-sky imaging photometer (ASIP) recorded $160^{\circ}$ field-of-view images of the dayside aurora in three different wavelengths $\left(427.8 \mathrm{~N}_{2}{ }^{+}, 557.7 \mathrm{O}[\mathrm{I}]\right.$, and $630.0 \mathrm{O}[\mathrm{nm})$. The three filters were cycled once per minute, with individual exposures requiring $2 \mathrm{~s}$. In addition, two Ebert-Fastie scanning spectrometers measured the absolute intensities of the $391.4 \mathrm{~nm} \mathrm{~N}_{2}{ }^{+}\left(\mathrm{I}_{3} 91.4=3 \times \mathrm{I}_{42} 27.8\right)$ and $630.0-\mathrm{nm}$ emissions with a $5^{\circ} \times 7^{\circ}$ field of view centered in the aircraft zenith. The all-sky images were used for assessing the overall structure and dynamics of the cusp-region aurora, while the spectrometer provided accurately calibrated absolute intensities (and intensity ratios). The 630.0-nm emission intensities $(2-4 \mathrm{kR})$ and the $\mathrm{I}(630.0 \mathrm{~nm}) / \mathrm{I}(391.4 \mathrm{~nm})$ ratios $(\sim 10-15)$ are consistent with the soft $(<200 \mathrm{eV})$ electron precipitation expected for cusp aurora [Rees and Luckey, 1974; Cogger et al., 1977; Eather et al., 1979; Sandholt, 1988].

The most striking morphological change in the ASIP images was the appearance of zonally elongated fingers of emission, or "rays," whenever the magnitude of $B y$ was large compared to the magnitude of $B_{Z}$. The four all-sky images shown in Figure 3 illustrate this correlation. These images have been transformed to geographic coordinates (north at the top) using an assumed emission height of $250 \mathrm{~km}$. The magnitudes of $B y$ and $B_{z}$ are noted in the upper right of each image. The images at 0535 and 0745 UT display elongated emission features stretching (predominately) to the west, while the other two images show relatively unstructured emission.

The 1-min resolution images were closely examined during the appearance of the elongated features. For the event at 0535 UT, they clearly show that two distinct faint arcs brightened to the west of the AIO to form the features shown in Figure 3. After approximately 6-10 min, the bright arcs faded and the coherent structure to the west dissipated. Since the exposure time of each image is $2 \mathrm{~s}$, there is very little blurring during the exposure. The intensity of the emissions are slightly diminished at the edges of the images, however, due to a combination of reduced sensitivity and lens defocusing. This vignetting can cause the 630.0-nm aurora to appear localized, when it may actually extend beyond the field of view. Since all images are subject to the same vignetting, however, we believe that differences in auroral structure between successive images are real.

The DE 1 satellite, traveling from pole to equator, passed through the ASIP field of view between 0530 and 0555 UT. Precipitating $\mathrm{H}^{+}$and $\mathrm{O}^{+}$ions, measured by the energetic ion composition spectrometer (EICS) are shown in Plate 1. Sheathlike $\mathrm{H}^{+}$ions are encountered between 0545 and 0549 UT. The energies of the $\mathrm{H}^{+}$ions display a slight reverse dispersion, decreasing in energy from high to low latitudes (0547 - 0549 UT). The region of most intense $\mathrm{H}^{+}$ precipitation, marked by a box on the footprint of the DE trajectory in Figure 3, occurs at the same invariant latitude as the maximum intensity $630.0-\mathrm{nm}$ emissions. The reverse dispersion is also seen in the weak, precipitating $\mathrm{O}^{+}$fluxes. 


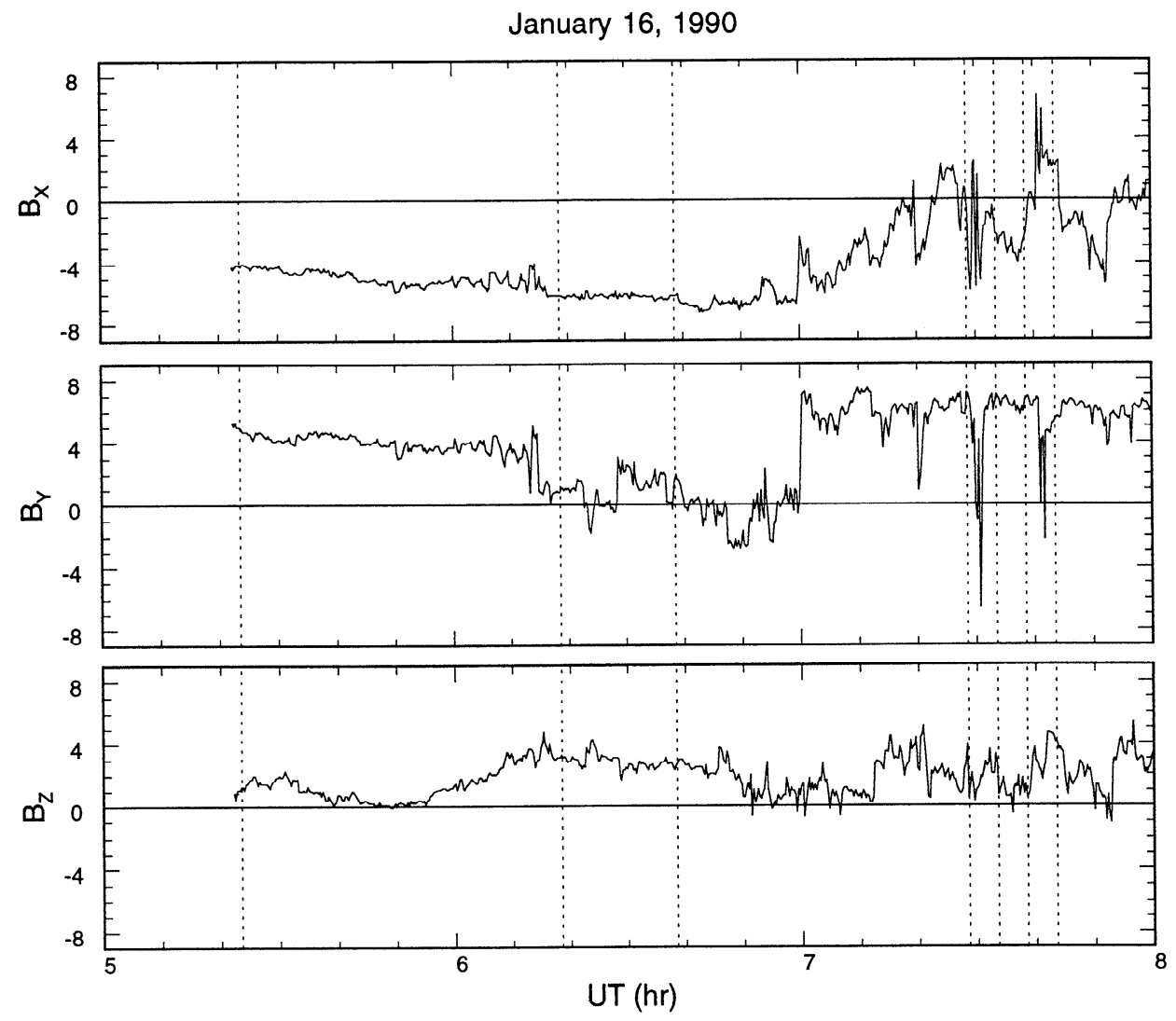

Figure 2. GSM $B_{x}, B_{y}$, and $B_{z}$ components of the IMF for the period $0500-0800$ UT, January 16 , 1990. The IMP 8 spacecraft was located at an average GSM position of $(29.3,11.7,7.4) R_{E}$, corresponding to a solar wind delay time of about $11.5 \mathrm{~min}$. The vertical dashed lines indicate the IMF conditions for the events in Figures 3 and 5. (High time resolution data courtesy Ron Lepping and NDADS.)

The source of this $\mathrm{O}^{+}$may be ions, originally part of the cleft ion fountain or turbulent entry layer, which are accelerated earthward as a result of lobe merging near the cusp.

Toward the end of the flight the ASIP and EISCAT fields of view overlapped. The EISCAT radar was using the "Polar" beamswing technique to obtain two-dimensional ionospheric flow vectors in the region north of Troms $\varnothing$. The technique is described in detail by Willis et al. [1986] and Lockwood [1991] . Figure 4 shows the derived (at the bisector of the two radar beams) velocity vectors overlaid on a series of four images from 0740 to 0755 UT. During this time, $B_{y}>B_{z}>0$ (see Figure 2). The flow vectors clearly show that the 630.0 $\mathrm{nm}$ rays are aligned with latitudinally narrow, strong flows in the ion vclocity $(\sim 1 \mathrm{~km} / \mathrm{s})$, which persist for 5-15 min. The strong westward flow is consistent with the field curvature force on newly opened field lines for the observed positive IMF $B_{y}$. If these flow bursts are indicative of newly opened field lines as we believe, the cusp footprint extends at least to 1040 MLT (the location of the AIO) at this time.

\section{Discussion}

The fact that the high-flow regions in the EISCAT data coincide with elongated emission features can be explained by the mechanism illustrated in Figure 5. A newly reconnected field line will be transported into the tail lobe, first under the action of the field line curvature (tension) force and subsequently by magnetosheath flow. There is a limited time $d t$ for which the precipitation yielding strong $630.0-\mathrm{nm}$ emission is seen on each newly opened (or reconfigured) field line, due to the reduction of the injected fluxes near the magnetosheath Alfvén line. (Recall that quasi-neutrality allows strong magnetosheath electron precipitation only where the bulk of the ions precipitate [Burch, 1985]). This time $d t$ will depend upon the reconnection site, the sheath flow, and the sheath field orientation. Under high-flow conditions ions injected at the merging point experience a greater degree of velocity dispersion, and thus a longer ground track, than ions injected under slow-flow conditions (Figure 5a). If strong- $B_{y}$ conditions also exist, the ion ground track and $630.0-\mathrm{nm}$ emission will be azimuthally extended (in the direction opposite to $B_{y}$ ) downstream of the $\mathrm{x}$ line (Figures $5 \mathrm{~b}$ and 5c). Even lobe reconnection (Figure 5c) yields flows extending to the dawnside for $B y$ positive conditions [Crooker, 1979, Reiff and Burch, 1985].

With this explanation in mind, we interpret the periodic appearance of azimuthally extended emission features in the earlier all-sky images (those without coincident EISCAT measurements) as indirect evidence of enhanced ionospheric flow (i.e., periods of enhanced dayside or lobe reconnection). The occurrence and direction of the optical rays / flow bursts are controlled by the IMF in a manner consistent with the tension forces on newly opened flux tubes: in the first and fourth images in Figure 3, rays appear to emanate to the west 

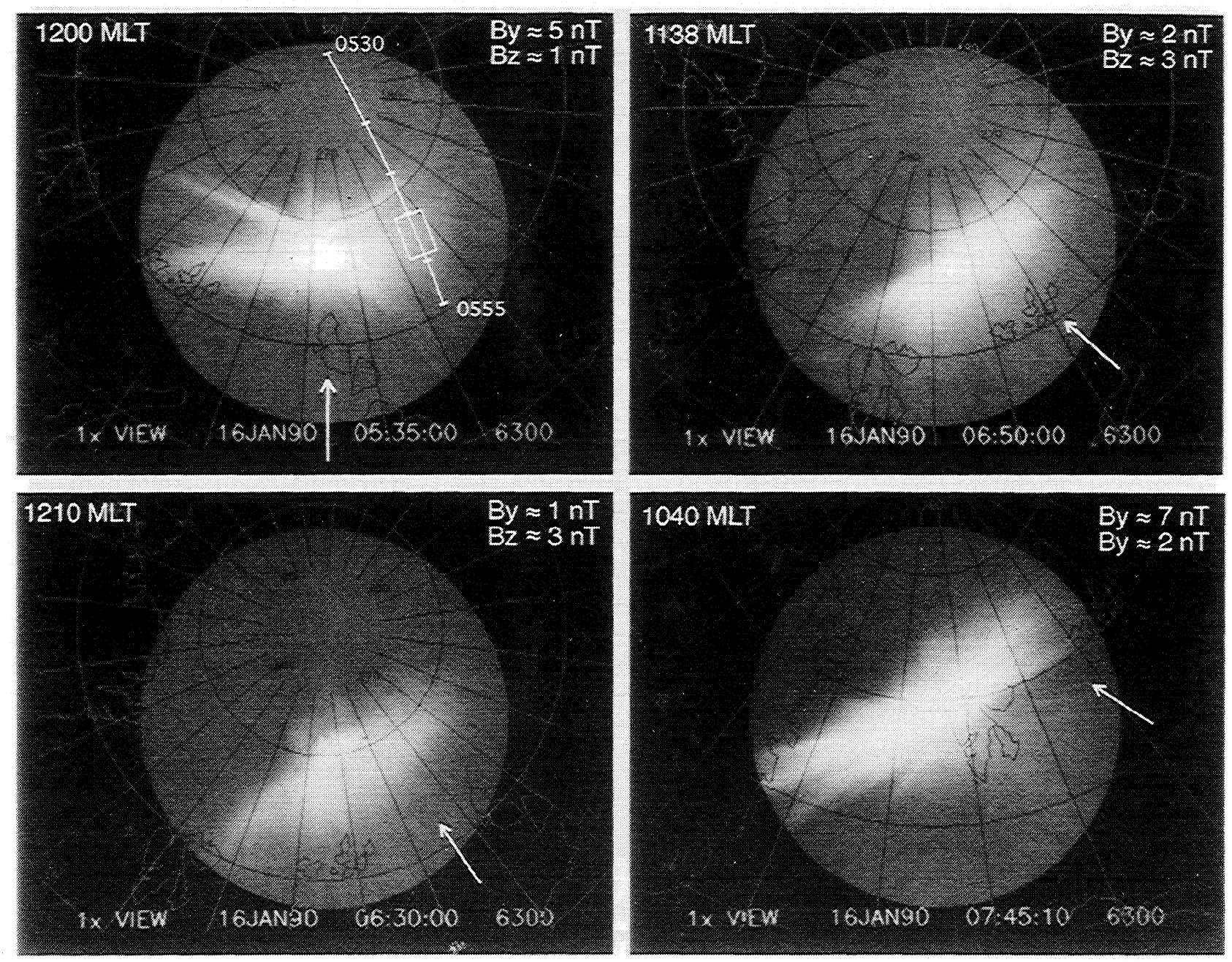

Figure 3. Four representative $630.0-\mathrm{nm}$ all-sky images illustrating the correlation between the appearance of zonally elongated fingers of emission and the ratio of $\left|B_{y}\right| /\left|B_{z}\right|$. When the $B_{y}$ component is larger than $B_{z}$ (top left and bottom right), rays emanate from the centroid of the precipitation; otherwise the distribution is relatively unstructured. The local time of each image is noted at the top left and the 12 MLT meridian is marked with an arrow.

from a basically oval centroid, consistent with the dawndirected convection velocity expected for $B y \gg 0$ [e.g., Crooker, 1979, 1988; Reiff and Burch, 1985]. In the other two images, $|B y| \leq\left|B_{z}\right|$, so highly asymmetric dawn-dusk flows are not expected (and are not observed). During the short period of time when $B y<0$ (0640 - 0655 UT), one might have expected the location of the cusp to shift dawnward and to appear with dusk-directed flow jets; perhaps due to the short duration of negative $B y$, neither signature appears in the images (but could have occurred out of our field of view to the east). We also suggest that while the central portion of the 630.0-nm emission represents the "cusp proper" where the 1 $2 \mathrm{keV}$ ions precipitate, the extended rays are the footprint of the low-energy extension of the cusp precipitation (i.e., the mantle). Pinnock et al. [1993] also showed DMSP and PACE HF radar observations which clearly demonstrated an extended, enhanced convection channel downstream of the cusp ion precipitation region (cf. their Plates 2 and 3).

The dispersion signature observed by low-altitude satellites passing through the cusp depends on the satellite's proximity to the merging line(s) and on any discontinuities in either the merging line or the ionospheric flow. Figures $5 \mathrm{~d}, 5 \mathrm{e}$, and $5 \mathrm{f}$ schematically illustrate these dependencies by showing for each case (slow flow, strong azimuthal flow, and strong azimuthal flow with lobe reconnection) the precipitating ion energies expected along two sample flow lines. Also shown are possible crossings of the region by polar-orbiting spacecraft (dotted lines). As discussed above, an elongated dispersion is observed in regions where the ion flow velocity is largest (e.g. the poleward flow paths in Figures 5e and 5f). Note in Figure 5d that almost any crossing of the distribution would show a "normal" energy dispersion, i.e., energies falling from low to high latitudes. In Figures $5 \mathrm{e}$ and $5 \mathrm{f}$, however, the observed dispersion depends on how the spacecraft trajectory cuts through the region. In Figure 5e, a spacecraft traveling from point $q$ to point $r$ would see a dispersion that falls in latitude until it reached the high-flow region, where the energy would rise before falling again. If the dayside $x$ line were broken into segments or if there were a truly discontinuous flow velocity in the ionosphere (caused by a flow discontinuity in the magnetosheath), the dispersion signature would appear to jump up discontinuously. Thus a 


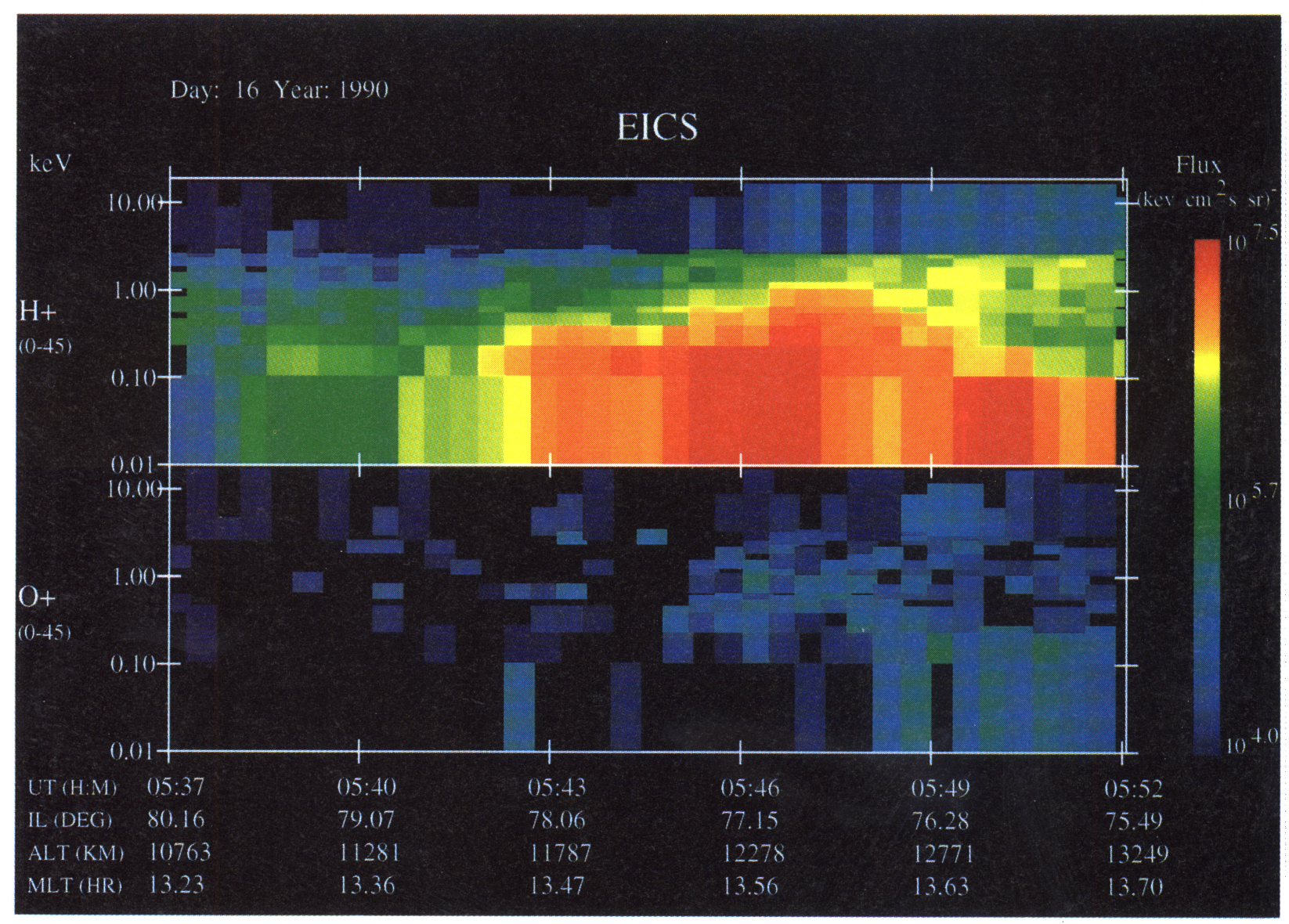

Plate 1. Precipitating $\mathrm{H}^{+}$and $\mathrm{O}^{+}$ions measured by DE 1 during its passage through the northern hemisphere cusp region. The satellite was traveling equatorward at an altitude of about $12,000 \mathrm{~km}$. The most intense fluxes of magnetosheath $\mathrm{H}^{+}$ions $\left(\sim 10^{7} \mathrm{keV} \mathrm{cm}^{-2} \mathrm{~s}^{-1} \mathrm{sr}^{-1}\right)$ are observed between 0545 and 0549 UT. Reversed dispersion is seen in both $\mathrm{H}^{+}$and $\mathrm{O}^{+}$between 0547 and $0549 \mathrm{UT}$, with peak $\mathrm{O}^{+}$ fluxes $\sim 10^{5} \mathrm{keV} \mathrm{cm}^{-2} \mathrm{~s}^{-1} \mathrm{sr}^{-1}$.

"stair-step" dispersion signature as seen by Escoubet et al. [1992] may not necessarily be a result of impulsive reconnection, but could simply represent a discontinuity in the flow velocity across the spacecraft trajectory. This latter interpretation is supported by recent observations of a stairstep dispersion signature recorded by DE 1 and 2 at nearly the same local time over $20 \mathrm{~min}$ apart [Onsager et al., 1995].

Figure $5 \mathrm{f}$ shows the ion dispersion energies expected during periods of lobe reconnection. A spacecraft crossing from $u$ to $v$ would see a truly discontinuous ion dispersion as it crossed from a flow path connected to the dayside $x$ line to a flow path connected to the lobe $x$ line. Whether that discontinuity would be a step up or down in energy would depend on the difference in the time along the flow path from each $x$ line. A spacecraft crossing from $y$ to $z$ would see a "reverse" dispersion signature: highest energies at the highest latitudes, much as was seen in this case by DE 1 . A spacecraft crossing from $x$ to $z$ would see highest energies at both high and low latitudes, with a minimum energy in between. We suggest that this type of cusp configuration is the source of the large-scale ion $\mathrm{V}$ distributions observed for northward IMF [Reiff et al., 1977, 1980; Burch et al., 1980]. Similar large-scale V distributions can be seen in the cusp data of Woch and Lundin [1992; Figure 3] and Yamauchi et al. [1993, Figure 2]; the former also shows large zonal flows at the edges of the cusp precipitation region.
Figure 6 shows an all-sky image taken at 0545 UT, close to the time that DE 1 saw reversed-dispersion cusp ion precipitation. This dispersion signature indicates a sunward convection component in the cusp region at this time, or at least a satellite trajectory in which the poleward portion of the trajectory passed closest to the lobe $x$ line (e.g., path $y-z$ in Figure 5f). We have overlaid a possible convection pattern (similar to Figure 5c) which accounts for a reverse dispersion within a generally westward flow. One possible location of the $\mathrm{x}$ line consistent with the observed dispersion is shown with dotted lines: one segment corresponds to magnetic merging on the dayside, and the other segment (nearer DE 1) corresponds to magnetic merging of the IMF with lobe field lines. Merging in either location will yield a westward outflow consistent with the rays, but the proximity of the spacecraft trajectory to the lobe $\mathrm{x}$ line is more consistent with the reversed energy dispersion observed by DE 1 .

Finally, we note that when the flow-aligned jets appear in the images, they typically persist for $5-15 \mathrm{~min}$, with one event lasting $25 \mathrm{~min}$. Lockwood and Cowley [1988] and Cowley and Lockwood [1992] make the point that once a field line has been opened (or reconfigured by lobe reconnection), zonal flows in the ionosphere will last for an extended period while the curvature force decays (i.e., the field line straightens). If the flow jets (extended emission features) are the result of enhanced reconnection pulses when $\left|B_{y}\right|>\left|B_{z}\right|$, 

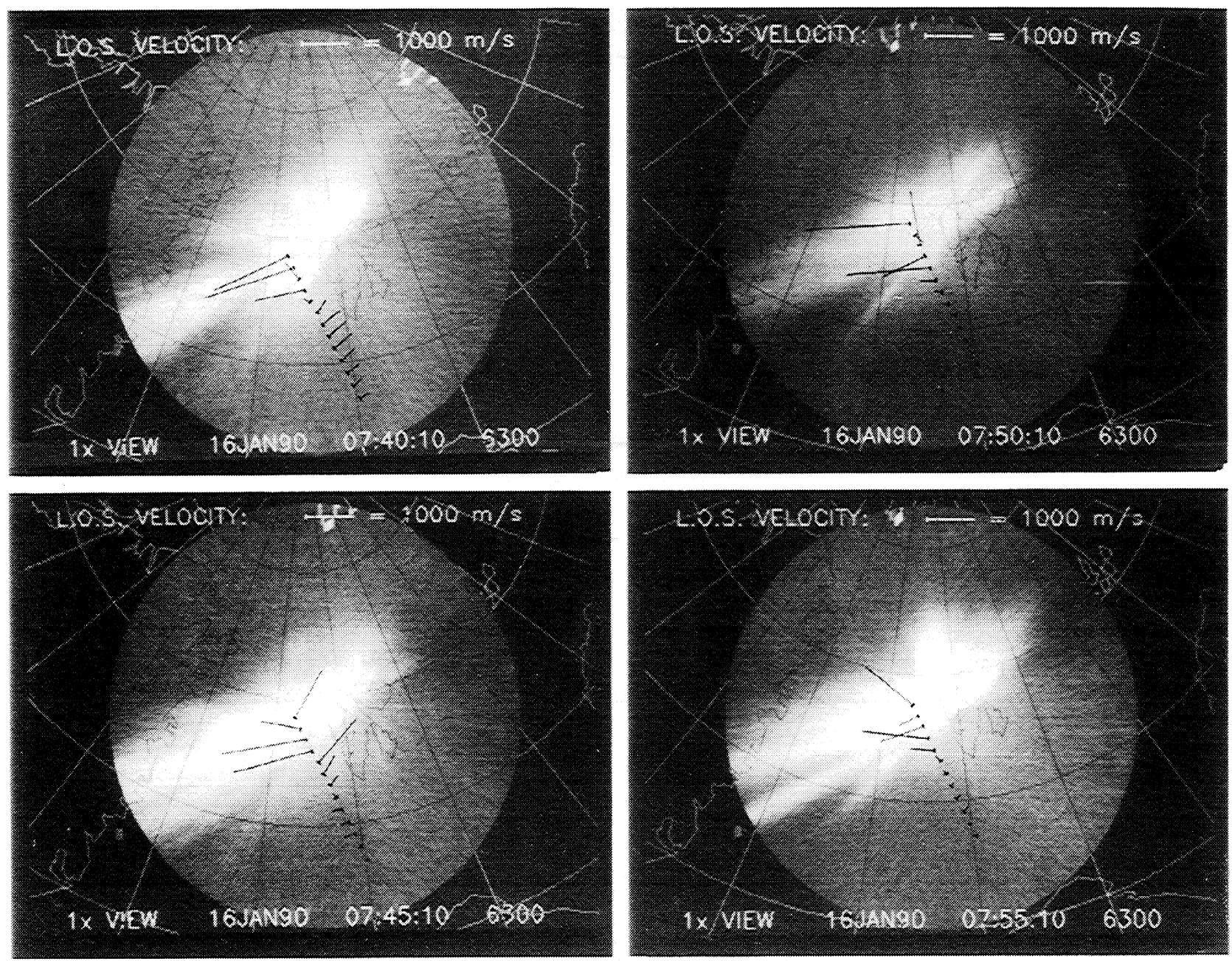

Figure 4. Two-dimensional flow velocities, derived from the "Polar" beamswing technique, superimposed on four ASIP images from 0740 to 0755 . The elongated optical emissions are aligned along the direction of the high flow velocities.

the duration of the pulses must be less than the observed durations of the optical rays (if the pulses are sufficiently close together in time, the rays will appear continuous, which they do not). The extent of the 630.0-nm emission along a flow stream line is $V d t$, where $V$ is the convection speed and $d t$ is the duration of the precipitation on any one newly opened field line which gives rise to 630.0-nm emission. The overlapped optical / EISCAT observations reveal that the extent of the rays $(V d t)$ and the convection speed $(V)$ are roughly correlated and hence that the interval $d t$ is relatively constant during this time. Given that the optical jets extend at least $500 \mathrm{~km}$ and the EISCAT data reveal that within them $V$ is roughly $1 \mathrm{~km} / \mathrm{s}$, we derive a minimum value of $d t$ of $500 \mathrm{~s}$. This is quite reasonable; a $150-200 \mathrm{eV}$ ion (typically the lowest energy cusp ions for which the electron precipitation is significant) has a field-aligned velocity of $170-200 \mathrm{~km} / \mathrm{s}$; $500 \mathrm{~s}$ corresponds therefore to a field-aligned distance of 13 $15 R_{E}$ to the $\mathrm{x}$ line, which is reasonable given magnetic field models and is consistent with previous estimates [e.g., Carlson and Torbert, 1980; Menietti and Burch, 1988].

\section{Summary}

The observations presented here show transient dayside auroral jets, associated with plasma flow enhancements, which behave in the same manner as that suggested for newly opened flux tubes; i.e., flow jets appear when $\left|B_{y}\right|>B_{z}$ and are directed opposite to the direction of $B_{y}$. A simple model of why the high-flow regions appear as elongated optical rays is suggested: under high-flow conditions (i.e., enhanced reconnection electric fields) ions injected at the merging point have a longer ground track $V d t$ than those injected under slow-flow (background) conditions; due to the requirement of quasi-neutrality, the region of precipitating electron flux and thus $630.0-\mathrm{nm}$ emission is also longer. It is significant that the flow jets are intermittent and transient, with durations of tens of minutes. The optical jets are interpreted as evidence of enhanced reconnection which, under northward IMF conditions, occurs predominantly when $|B \boldsymbol{y}|>B_{z}$. We have presented a possible convection pattern, involving both dayside and lobe reconnection, which accounts for the reversed ion dispersion seen by DE 1 in conjunction with the strong westerly flow. It is suggested that if periods of enhanced reconnection occur at these locations, the duration of the reconnection is less than the duration of the flow-aligned jets, which varies between 5 and $25 \mathrm{~min}$. Given that the precipitation within the jets lasts for $\geq 8 \mathrm{~min}$, we conclude that the reconnection pulses last for $\sim 0-17 \mathrm{~min}$. One must keep in mind, however, that little direct evidence exists which links the transient dayside ionospheric phenomena discussed 


\section{Weak flow}

$\left|B_{y}\right|<\left|B_{z}\right|<3 n T$
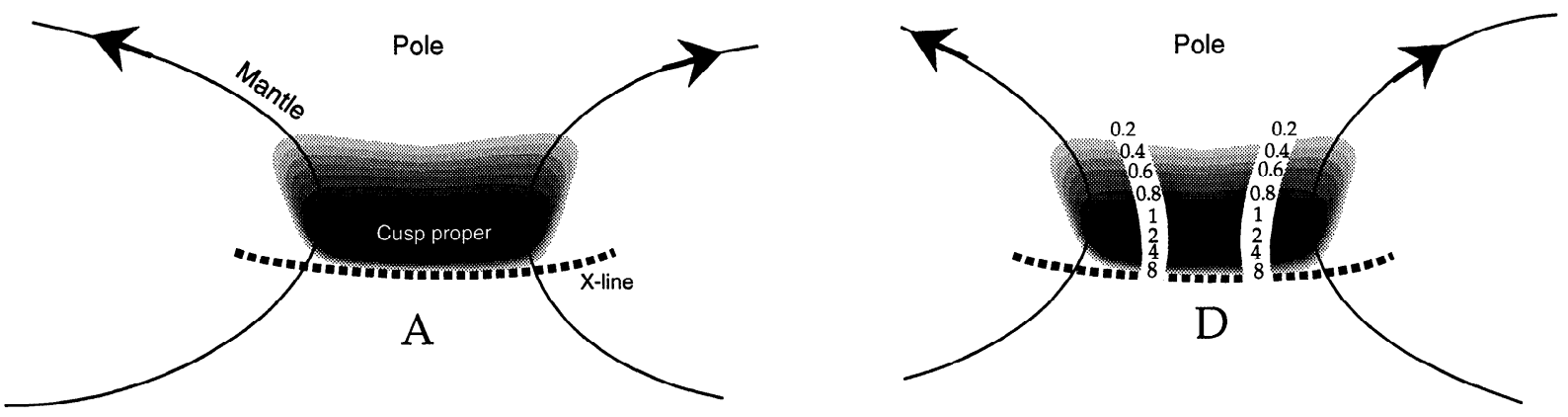

Flow jets

$$
\left|B_{y}\right|>\left|B_{z}\right|, B_{z}<0
$$

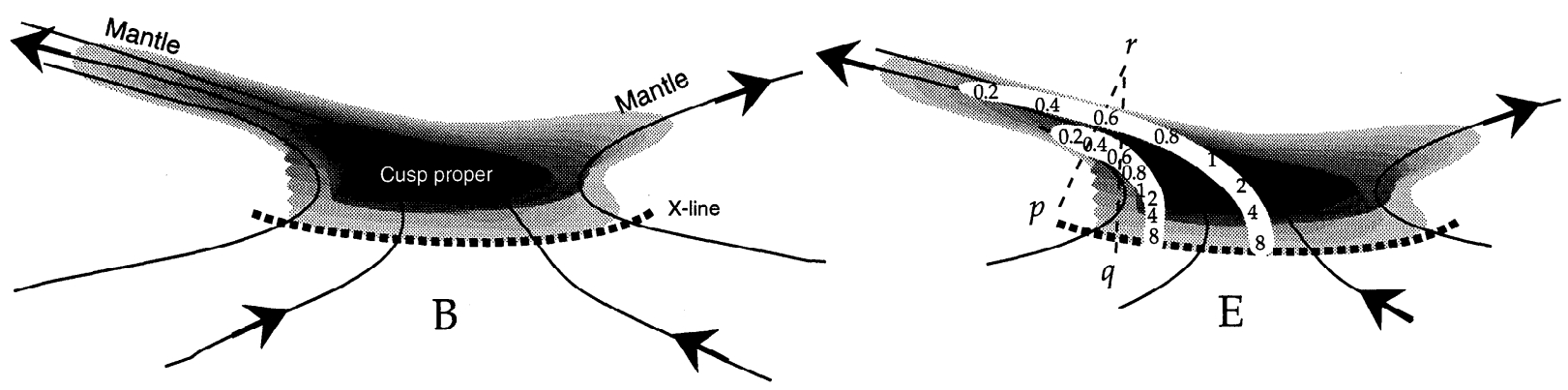

\section{Flow jets with lobe reconnection}

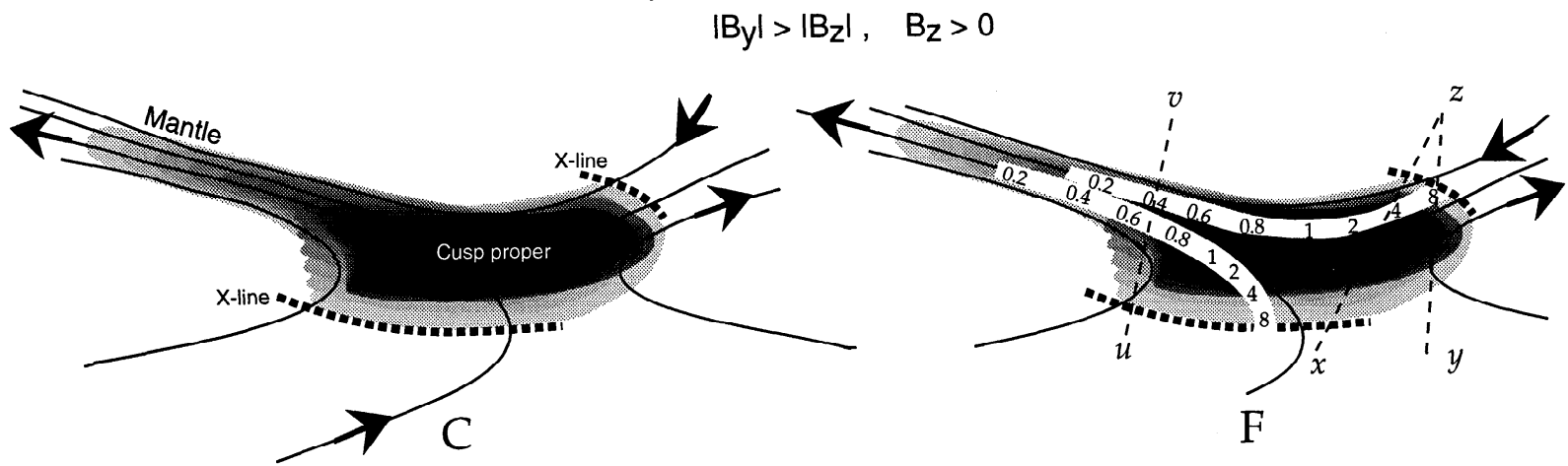

Figure 5. Schematic diagram showing cusp precipitation patterns (and $6300 \AA$ emission) expected for times of (a) weak flow, and (b and c) strong $B y$-dependent flow. Noon is toward the bottom of each figure. (c) differs from Figure $5 \mathrm{~b}$ in that some of the westward directed flow originates from a lobe merging $x$ line in the polar cap. The flux is most intense (darkest) slightly downstream from the $x$ line, where the $1-2 \mathrm{keV}$ ions precipitate. The fluxes are also largest near noon because those field lines map to the stagnation region at the nose of the magnetosphere, where the sheath density is the largest. Flow paths which cross the $x$ line farther from noon have weaker source densities and thus lower fluxes. The contours are stretched in the direction of the flow, since the ion dispersion distance $v d t$ is larger where the convection velocity is larger ( $d t$ is observed to be $\sim 500 \mathrm{~s}$ ). Sample precipitating ion energies (keV) for each of the flow configurations are shown on the left. Lobe reconnection $(f)$ can yield a reversed dispersion signature on the afternoon side as observed by DE 1, which traveled approximately from point $z$ to point $y$. A spacecraft traveling from $x$ to $z$ would observe a V-shaped ion dispersion, with the minimum energy at the transition between sources. 


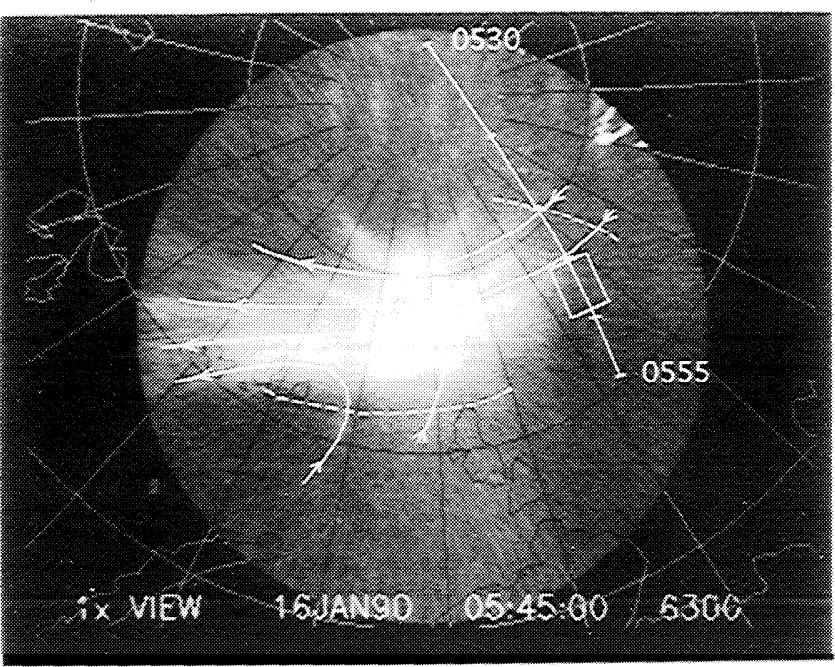

Figure 6. Possible ionospheric flow lines (similiar to Figure 5f) overlaid on an all-sky image at 0545 UT. The flow paths are consistent with the optical jets and the reverse dispersion observed by EICS on DE 1.

here to FTE signatures at the magnetopause; the only examples being those presented by Elphic et al. [1990] and Sandholt et al. [1992].

Acknowledgments. This work was supported at Rice University by National Science Foundation grant ATM92-12573 and NASA grant NAGW-1655. Work performed at Los Alamos National Laboratory was conducted under the auspices of the Department of Energy. At Phillips Laboratory this work was supported by AFOSR under Task 231069. DE EICS data analysis at Lockheed was performed under NASA contract NAS5-33032. The authors gratefully acknowledge Pat Newell, Michelle Thomsen, Mark Moldwin, Terry Onsanger, and Gang $\mathrm{Lu}$ for useful discussions and insight, Pat Shopbell for work involved in plotting the color spectrograms, and Peter Ning, Vaughn Hickman, Earl Scime, and David Oró for assistance with the optical images. We also thank the director and staff of the EISCAT Scientific Association; EISCAT is supported by the research councils of France, German, Sweden, Norway, Finland, and the United Kingdom.

The Editor thanks T. Mukai and another referee for their assistance in evaluating this paper.

\section{References}

Aparicio, B., B. Thelin, and R. Lundin, The polar cusp from a particle point of view: A statistical study based on Viking data, J. Geophys. Res., 96, 14023, 1991.

Baker, K. B.., R. A. Greenwald, A. D. M. Walker, P. F. Bythrow, T. A. Potemra, D. A. Hardy, F.J. Rich, and C.L. Rino, A case study of plasma processes in the dayside cleft, J. Geophys. Res., 91, 3130, 1986.

Baker, K. B., R. A. Greenwald, J. M. Ruohoniemi, J. R. Dudeney, M. Pinnock, P. T. Newell, M. E. Greenspan, and C.-I. Meng, Simultancous HF-radar and DMSP observations of the cusp, Geophys. Res. Lett., 17, 1869, 1990.

Baker, K. B., R. A. Greenwald, P. T. Newell, C.-I. Meng, J. R. Dudeney, A. S. Rodger, M. Pinnock, and N. Mattin, HF-radar signatures of the cusp and the low-latitude boundary layer, this issue.

Basinska, E. M., W. J. Burke, N. C. Maynard, W. J. Hughes, J. D. Winningham, and W. B. Hanson, Small-scale electrodynamics of the cusp with northward interplanetary magnetic field, J. Geophys. Res., 97, 6369, 1992.

Bosqued, J. M., A. Berthelier, J. J. Berthelier, and C. P. Escoubet, A case study of the cusp electrodynamics by the Aureol-3 satellite: Evidence for FTE signatures? Geophys. Res. Lett., 18, 1833, 1991.

Burch, J. L., Rate of erosion of dayside magnetic flux based on a quantitative study of the dependence of polar cusp latitude on the interplanetary magnetic field, Radio Sci., 8, 955, 1973.
Burch, J. L., Quasi-neutrality in the polar cusp, Geophys. Res. Lett. , 12, 469-472, 1985.

Burch, J. L., P. H. Reiff, R. W. Spiro, R. A. Heelis, and S. A. Fields, Cusp region particle precipitation and ion convection for northward interplanetary magnetic field, Geophys. Res. Lett., 7, 393, 1980.

Burch, J. L., P. H. Reiff, R. A. Heelis, J. D. Winningham, W. B. Hanson, C. Gurgiolo, J. D. Menietti, R. A. Hoffman, and J. N. Barfield, Plasma injection and transport in the mid-altitude polar cusp, Geophys. Res. Lett., 9, 921, 1982.

Burch, J. L., J. D. Menietti, and J.N. Barfield, DE-1 observations of solar wind-magnetosphere coupling processes in the polar cusp, in Solar Wind - Magnetosphere Coupling, edited by Y. Kamide and J. A. Slavin, p. 441, Terra Scientific, Tokyo, 1986.

Candidi, M., H. W. Kroehl, and C. -I. Meng, Intensity distribution of dayside polar soft electron precipitation and the IMF, Planet. Space Sci., 31, 489, 1983.

Carbary, J.F., and C.-I. Meng, Correlation of cusp latitude with $B z$ and $A E(12)$ using nearly one year's data, J. Geophys. Res., 91, 10047, 1986.

Carlson, C. W., and R. B. Torbert, Solar wind ion injections in the morning auroral oval, J. Geophys. Res., 85, 2903, 1980.

Carlson, H., and Su. Basu, GEM Pilot Program, in Geospace Environment Modeling: Workshop Report on Intercalibrating Cusp Signatures, vol. GEM WSR-3, p. 101, Magnetospheric Physics Program, National Science Foundation, Washington, D. C., 1990.

Clauer, C.R., and P.M. Banks, Relationship of the interplanetary electric field to the high-latitude ionospheric electric field and currents: Observations and model simulations, J. Geophys. Res., 91, 6959, 1986.

Cogger, L. L., J. S. Murphree, S. Ismail, and C. D. Anger, Characteristics of dayside $5577 \AA$ and $3914 \AA$ aurora, Geophys. Res. Lett., 4, 413, 1977.

Cowley, S. W. H., D. J. Southwood, and M. A. Saunders, Interpretation of magnetic field perturbations in the Earth's magnetopause boundary layers, Planet. Space Sci., 31, 1237, 1983.

Cowley, S.W.H., J.P. Morelli, and M. Lockwood, Dependence of convective flows and particle precipitation in the high-latitude dayside ionosphere on the $X$ and $Y$ components of the interplanetary magnetic field, J. Geophys. Res., 96, 5557, 1991.

Cowley, S. W. H., and M. Lockwood, Excitation and decay of solarwind driven flows in the magnetosphere-ionosphere system, Ann. Geophys., 10, 103, 1992.

Crooker, N. U., Dayside merging and cusp geometry, J. Geophys. Res., $84,951,1979$.

Crooker, N. U., Mapping the merging potential from the magnetopause to the ionopshere through the dayside cusp, J. Geophys. Res., 93, $7338,1988$.

Eather, R. H., S. B. Mende, and E. J. Weber, Dayside aurora and relevance to substorm current systems and dayside merging, $J$. Geophys. Res., 84, 3339, 1979.

Elphic, R. C., M. Lockwood, S.W.H. Cowley, and P.E. Sandholt, Flux transfer events at the magnetopause and in the ionosphere, Geophys. Res. Lett. ., 17, 2241, 1990.

Escoubet, C.P., and J.M. Bosqued, The influence of IMF-Bz and/or AE on the polar cusp: An overview of observations from the Aureol-3 satellite, Planet. Space Sci., 37, 609, 1989.

Escoubet, C.P., M.F. Smith, S.F. Fung, P.C. Anderson, R.A. Hoffman, E.M. Basinska, and J. M. Bosqued, Staircase ion signatures in the polar cusp: A case study, Geophys. Res. Lett., 19, 1735, 1992.

Etcmadi, A., S. W. H. Cowley, M. Lockwood, B. J. I. Bromage, D. M. Willis, and $H$. Luhr, The dependence of high-latitude dayside ionospheric flows on the north-south component of the IMF: A high time resolution correlation analysis using EISCAT, "POLAR," and AMPTE UKS and IRM data, Planet Space Sci., 36, 471, 1988.

Frahm, R. A., Cusp particle detection and ion injection source oscillations, M.S. thesis, Rice Univ., Houston, Tex., 1984.

Goertz, C. K., E. Neilsen, A. Korth, K.-H. Glassmeier, C. Haldoupis, P. Hoeg, and D. Hayward, Observations of a possible ground signature of flux transfer events, J. Geophys. Res., 90, 4069, 1985.

Gosling, J.T., J.R. Asbridge, S.J. Bame, W.C. Feldman, G. Paschmann, N. Sckopke, and C.T. Russell, Evidence for quasi-stationary reconnection at the dayside magnetopause, J. Geophys. Res., 87, $2147,1982$.

Gosling, J. T., M. F. Thomsen, S. J. Bame, and C. T. Russell, Accelerated plasma flows at the near-tail magnetopause, $J$. Geophys. Res., 91, 3029, 1986.

Gosling, J.T., M.F. Thomsen, S.J. Bame, R.C. Elphic, and C.T. Russell, 
Plasma flow reversals at the dayside magnetopause and the origin of asymmetric polar cap convection, J. Geophys. Res., 95, 8073, 1990.

Greenwald, R.A., K.B. Baker, J.M. Ruohoniemi, J.R. Dudeney, M. Pinnock, N. Mattin, J.M. Leonard, and R.P. Lepping, Simultaneous conjugate observations of dynamic variations in high-latitude dayside convection due to changes in IMF By, J. Geophys. Res., 95, 8057, 1990.

Heelis, R.A., The effects of interplanetary magnetic field orientation on dayside high-latitude convection, J. Geophys. Res., 89, 2873, 1984.

Heikkila W. J., Definition of the cusp, in The Polar Cusp, edited by J. Holtet and A. Egeland, p. 387-395, D. Reidel, Norwell, Mass., 1985.

Heppner, J. P., and N. C. Maynard, Empirical high-latitude electric field models, J. Geophys. Res., 92, 4467, 1987.

Hill, T. W., and P. H. Reiff, Evidence of magnetospheric cusp proton acceleration by magnetic merging at the dayside magnetopause, $J$. Geophys. Res., 82, 3623, 1977.

Lockwood, M., The excitation of ionospheric convection, J. Atmos. Terr. Phys., 53, 177, 1991.

Lockwood, M., and S. W. H. Cowley, Observations at the magnetopause and in the auroral ionosphere of momentum transfer from the solar wind, Adv. in Space Res., 8, (9/10)281, 1988.

Lockwood, M., P. E. Sandholt, and S. W. H. Cowley, Dayside auroral activity and magnetic flux transfer from the solar wind, Geophys. Res. Lett., 16, 33, 1989a.

Lockwood, M., P. E. Sandholt, S. W. H. Cowley, and T. Oguti, Interplanetary magnetic field control of dayside auroral activity and the transfer of momentum across the dayside magnetopause, Planet. Space Sci., 37, 1347, 1989b.

Lockwood, M., and M.F. Smith, The variation of reconnection rate at the dayside magnetopause and cusp ion precipitation, J. Geophys. Res., 97, 14841, 1992.

Lockwood, M., W. F. Denig, A. D. Farmer, V. N. Davda, S. W. H. Cowley, and $\mathrm{H}$. Luhr, Ionospheric signatures of pulsed magnetic reconnection at the Earth's magnetopause, Nature, 361(6411), 424$428,1993$.

Lockwood, M., S. W. H. Cowley, and M.F. Smith, Comment on "By fluctuations in the magnetosheath and azimuthal flow velocity transients in the dayside ionosphere" by Newell and Sibeck, Geophys. Res. Lett., 21, 1819, 1994.

Lyons, L.R., M. Schulz, D.C. Pridmore-Brown, and J.L. Roeder, The low latitude boundary layer near noon: An open field line model, in press, J. Geophys. Res., 99, 17367, 1994.

Maynard, N. C., W. F. Denig, and W. J. Burke, Mapping ionospheric convection pattems to the magnetosphere, J. Geophys. Res., 96 3505, 1991a.

Maynard, N. C., T. L. Aggson, E. M. Basinska, W. J. Burke, P. Craven, W. K. Peterson, M. Sugiura, and D. R. Weimer, Magnetospheric boundary dynamics: DE 1 and DE 2 observations near the magnetopause and cusp, J. Geophys. Res., 96, 3505, 1991 b.

Menietti, J. D., and J.L. Burch, Spatial extent of the plasma injection region in the cusp-magnetosheath interface, J. Geophys. Res., 93 , $105,1988$.

Mukai, T., A. Matsuoka, H. Hayakawa, S. Machida, K Tsuruda, A. Nishida and N. Kaya, Signatures of solar wind injection and transport in the dayside cusp: EXOS-D observations, Geophys. Res. Lett., 18, 333, 1991.

Newell, P.T., and C.-I. Meng, The cusp and the cleft/boundary layer: Low-altitude identification and statistical local time variation, $J$. Geophys. Res., 93, 14549, 1988.

Newell, P.T., and C.-I. Meng, On quantifying the distinctions between the cusp and the cleft/LLBL, in Electromagnetic Coupling in the Polar Clefts and Caps, edited by P. E. Sandholt and A. Egeland, p. 87, Kluwer Academic, Boston, Mass., 1989.

Newell, P. T., and D. G. Sibeck, By fluctuations in the magnetosheath and azimuthal flow velocity transients in the dayside ionosphere, Geophys. Res. Lett., 20, 1719, 1993.

Newell, P.T., C.-I. Meng, D.G. Sibeck, and R. Lepping, Some lowaltitude cusp dependencies on the interplanetary magnetic field, $J$. Geophys. Res., 94, 8921, 1989.

Newell, P.T., W.J. Burke, C.-I. Meng, E.R. Sanchez, and M.E. Greenspan, Identification of the plasma mantle at low altitude, $J$. Geophys. Res., 96, 35, 1991.

Oguti, T., T. Yamamoto, K. Hayashi, S. Kokubun, A. Egeland, and J.A. Holtet, Dayside auroral activity and related magnetic impulses in the polar cusp region, J. Geomagn. Geoelectr., 40, 387, 1988.

Onsager, T. G., C. A. Kletzing, J. B. Austin, and H. MacKiernan, Model of magnetosheath plasma in the magnetosphere: Cusp and mantle particles at low-altitudes, Geophys. Res. Lett., 20, 479-482, 1993.

Onsager, T. G., S.-W. Chang, J. D. Perez, J. B. Austin, and L. X. Jano, Low altitude observations and modeling of quasi-steady magnetopause reconnection, J. Geophys. Res., in press, 1995.

Paschmann, G., I. Papamastorakis, W. Baumjohann, N. Sckopke, C.W. Carlson, B.U. O. Sonnerup, and H. Luhr, The magnetopause for large magnetic shear: AMPTE/IRM observations, J. Geophys. Res., 91, $11099,1986$.

Paschmann, G., S.A. Fuselier, and D.M. Klumpar, High-speed flows of $\mathrm{H}^{+}$and $\mathrm{He}^{++}$ions at the magnetopause, Geophys. Res. Lett., 16, $567,1989$.

Phillips, J.L., S.J. Bame, R.C. Elphic, J.T. Gosling, M.F. Thomsen, and T.G. Onsager, Well-resolved observations by ISEE 2 of ion dispersion in the magnetospheric cusp, J. Geophys. Res., 98, 13429, 1993.

Pinnock, M., A. S. Rodger, J. R. Dudeney, K. B. Baker, P. T. Newell, R.A. Greenwald, and M. E. Greenspan, Observations of an enhanced convection channel in the cusp ionosphere, Geophys. Res., 98, 3767, 1993.

Rees, M. H., and D. Luckey, Auroral electron energy derived from ratio of spectroscopic emissions, 1, Model computations, J. Geophys. Res., 79, 5181, 1974.

Reiff, P. H., Low-altitude signatures of the boundary layers, in Magnetospheric Boundary Layers, edited by B. Battrick, Eur. Space Agency Spec. Publ., SP-148, 167-173, 1979.

Reiff, P. H., Some comments on all three questions, in Intercalibrating Cusp Signatures, Proceedings of the GEM workshop, edited by N. Crooker, p. 98, National Science Foundation, Washington, D. C., 1990.

Reiff, P. H., and J. L. Burch, IMF By-dependent plasma flow and Birkeland currents in the dayside magnetosphere, 2, A global model for northward and southward IMF, J. Geophys. Res., 90, 1595, 1985.

Reiff, P. H., T. W. Hill, and J.L. Burch, Solar wind plasma injection at the dayside magnetospheric cusp, J. Geophys. Res., 82, 479, 1977.

Reiff, P. H., J. L. Burch, and R. W. Spiro, Cusp proton signatures and the interplanetary magnetic field, J. Geophys. Res., 85, 5997, 1980.

Russell, C. T., and R. C. Elphic, ISEE observations of flux transfer events at the dayside magnetopause, Geophys. Res. Lett., 6, 33, 1979.

Saflekos, N.A., J.L. Burch, M. Sugiura, D.A. Burnett, and J. L. Horwitz, Observations of reconnected flux tubes within the mid-altitude cusp. J. Geophys. Res., 95, 8037, 1990.

Sandholt, P. E., IMF control of polar cusp and cleft auroras, Adv. Space Res., 8(9) 21, 1988.

Sandholt, P. E., A. Egeland, J. A. Holtet, B. Lybekk, K. Svenes, S. Asheim, and C. S. Dechr, Large- and small-scale dynamics of the polar cusp, J. Geophys. Res., 90, 4407, 1985.

Sandholt, P. E., and P. T. Newell, Ground and satellite observations of an auroral event at the cusp/cleft equatorward boundary, $J$. Geophys. Res., 97, 8685, 1992.

Sandholt, P. E., C. S. Deehr, A. Egeland, J. A. Holtet, B. Lybekk, R. Viereck, and G.J. Romick, Signatures in the dayside aurora of plasma transfer from the magnetosheath, J. Geophys. Res., 91, $10063,1986 \mathrm{a}$.

Sandholt, P. E., A. Egeland, and B. Lybekk, On the spatial relationship between auroral emissions and magnetic signatures of plasma convection in the midday polar cusp and cap ionospheres during negative and positive IMF Bz: A case study, J. Geophys. Res., 91, $12108,1986 b$.

Sandholt, P.E., M. Lockwood, W.F. Denig, R.C. Elphic, and S. Leontjev, Dynamical auroral structure in the vicinity of the polar cusp: Multipoint observations during southward and northward IMF, Ann. Geophys., 10, 483, 1992.

Saunders, M. A., C. T. Russell, and N. Sckopke, A dual-satellite study of spatial properties of FTEs, in Magnetic Reconnection in Space and Laboratory Plasmas, Geophys. Monogr. Ser., vol. 30, edited by E. W. Hones Jr., (ed.), p. 145, AGU, Washington, D.C., 1984.

Saunders, M.A., Origin of the cusp Birkeland currents, Geophys. Res. Lett., 15, 151, 1988.

Scholer, M., Magnetic flux transfer at the magnetopause based on single $\mathrm{x}$-line bursty reconnection, Geophys. Res. Lett., 15, 291, 1988.

Shelley, E.G., R.D. Sharp, and R.G. Johnson, He++ and H+ flux measurements in the dayside cusp: Estimates of convection electric field, J. Geophys. Res., 81, 2723, 1976.

Smith, M.F., and M. Lockwood, The pulsating cusp, Geophys. Res. Lett ., $17,1069,1990$ 
Sonnerup, B.U.O., G. Paschmann, I. Papamastorakis, N. Sckopke, G. Haerendel, S.J. Bame, J.R. Asbridge, J.T. Gosling, and C.T. Russell, Evidence for magnetic field reconnection at the earth's magnetopause, J. Geophys. Res., 86, 10049, 1981.

Southwood, D. J., C. J. Farrugia, and M. A. Saunders, What are flux transfer events?, Planet. Space Sci., 36, 503, 1988.

Todd, H., B.J.I. Bromage, S.W.H. Cowley, M. Lockwood, A.P. van Eyken, and D.M. Willis, EISCAT observations of bursts of rapid flow in the high latitude dayside ionosphere, Geophys. Res. Lett., 13, 909, 1986.

Watermann, J., O. de la Beaujardiere, and P. T. Newell, Incoherent scatter radar observations of ionospheric signatures of cusp-like electron precipitation, J. Geomagn. Geoelectr., 44, 1195, 1992.

Willis, D. M., M. Lockwood, S. W. H. Cowley, A. P. van Eyken, B. I. I. Bromage, H. Rishbeth, P. R. Smith, and S. R. Crothers, A survey of simultaneous observations of the high-latitude ionosphere and Interplanetary Magnetic Field with EISCAT and AMPTE-UKS, $J$. Atmos. Terr. Phys., 48, 987, 1986.

Woch, J., and R. Lundin, Magnetosheath plasma precipitation in the polar cusp and its control by the interplanetary magnetic field, $J$. Geophys. Res., 97, 1421, 1992.

Yamauchi, M., and R. Lundin, Classification of large-scale and meso- scale ion dispersion patterns observed by Viking over the cuspmantle region, in Physical Signatures of Magnetospheric Boundary Layer Processes, edited by J. A. Holtet and A. Egeland, p. 99, Kluwer Academic, Boston, Mass., 1994.

Yamauchi, M., J. Woch, R. Lundin, M. Shapshak, and R. Elphinstone, A new type of ion injection event observed by Viking, Geophys. Res. Lett., 20, 795, 1993.

H.C. Carlson and E.J. Weber, Phillips Laboratory, Hanscom Air Force Base, MA 01731.

M. Lockwood, Rutherford Appleton Laboratory, Chilton Oxon, OX11 OQX England.

W. K. Peterson, Lockheed Palo Alto Research Laboratory, Palo Alto, CA 94304.

P. H. Reiff, Department of Space Physics and Astronomy, Rice University, Houston, TX 77251.

L. A. Weiss, Space and Atmospheric Sciences, Los Alamos National Laboratory, P.O. Box 1663, MS D466, Los Alamos, NM 87545.

(Received February 16, 1994; revised December 19, 1994; accepted December 19, 1994.) 